\title{
TAKT TIME E BALANCEAMENTO NO FORMATO DA PROGRAMAÇÃO DE LINHA DE
}

\author{
PRODUÇÃO
}

\section{TAKT TIME AND BALANCING IN THE PRODUCTION LINE PROGRAMMING FORMAT}

\author{
Patrick Cemin ${ }^{1}$ \\ https://orcid.org/0000-0002-1249-7822 \\ Zaida Cristiane dos Reis ${ }^{2}$ \\ https://orcid.org/0000-0001-9029-1785 \\ Vandoir Welchen ${ }^{3}$ \\ https://orcid.org/0000-0001-7042-1239 \\ Juliana Matte ${ }^{4}$ \\ https://orcid.org/0000-0003-0945-2479 \\ Daniel Hank Miri ${ }^{5}$ \\ https://orcid.org/0000-0002-0765-6868 \\ Cassiane Chais $^{6}$ \\ https://orcid.org/0000-0002-1922-9273 \\ Paula Patrícia Ganzer ${ }^{7}$ \\ https://orcid.org/0000-0003-4006-6517 \\ Pelayo Munhoz Olea ${ }^{8}$ \\ https://orcid.org/0000-0003-2183-8112
}

Como citar este artigo: CEMIN, P. .; DOS REIS , Z. C. .; WELCHEN , V.; MATTE, J. .; MIRI, D. H.; CHAIS, C. C.; GANZER, P. P. G.; OLEA, P. M. O. TAKT TIME E BALANCEAMENTO NO FORMATO DA PROGRAMAÇÃO DE LINHA DE PRODUÇÃO. Revista Visão: Gestão Organizacional, Caçador (SC), Brasil, v. 10, n. 2, p. 42-58, 2021. DOI: 10.33362/visao.v10i2.2718. Disponível em: https://periodicos.uniarp.edu.br/index.php/visao/article/view/2718.

\footnotetext{
${ }^{1}$ Bacharel em Administração pelo Centro Universitário da Serra Gaúcha (FSG). E-mail: patrickcemin87@gmail.com.

2 Doutora em Administração pelo Programa de Pós-Graduação em Administração da Universidade de Caxias do Sul (UCS). E-mail: zcreis@gmail.com.

${ }^{3}$ Doutorando em Administração pelo Programa de Pós-Graduação em Administração da Universidade de Caxias do Sul (UCS).E-mail: vwelchen@ucs.br.

${ }^{4}$ Doutoranda em Administração pelo Programa de Pós-Graduação em Administração da Universidade de Caxias do Sul (UCS). E-mail: ju.cxs1@gmail.com.

${ }^{5}$ Doutorando em Administração pelo Programa de Pós-Graduação em Administração da Universidade de Caxias do Sul (UCS). E-mail: danielmirid@gmail.com.

${ }^{6}$ Doutora em Administração pelo Programa de Pós-Graduação em Administração da Universidade de Caxias do Sul (UCS). E-mail: cassichais@gmail.com.

7 Pós-doutorado em Administração pelo Programa de Pós-Graduação em Administração da Universidade de Caxias do Sul (UCS). E-mail: ganzerpaula@gmail.com.

8 Pós-doutorado em Gestão Ambiental pela Universidad de Extremadura (UEX), Espanha. E-mail: pelayo.olea@gmail.com.
} 
Resumo: Produzir mais, empregando menos tempo e menos recursos, é o sonho de qualquer empresa. Diante disso, este estudo busca resolver problemas de utilização da capacidade e de desnivelamentos de produção. Dessa maneira, o objetivo consiste em propor um formato de programação que otimize a utilização dos recursos e resulte em maior equilíbrio na produção de uma empresa do ramo metalúrgico, produtora de implementos rodoviários e localizada na região Sul do Brasil. Por meio de um estudo de caso, identificaram-se a forma de trabalho e a situação da programação da empresa. A partir disso, criou-se um modelo de um novo formato de produção, voltado à minimização das variações de volumes e fundamentado, basicamente, na utilização dos conceitos de takt time e de balanceamento das linhas. Conclui-se que o modelo proposto permitirá um ritmo continuado na produção, sendo capaz de estabilizá-la. Ademais, conforme for aplicado nas linhas da empresa, evidenciará os pontos ao longo do fluxo que precisam de melhoria, identificando gargalos e ociosidades. A soma de tais fatores proporcionará o aprimoramento contínuo dos processos da empresa e a otimização dos recursos disponíveis para a produção.

Palavras-Chave: Linha de produção. Programação de produção. Takt time. Balanceamento de linha. Capacidade produtiva.

Abstract: Producing more, using less time and fewer resources, is the dream of any company. Therefore, this study seeks to solve problems of capacity utilization and production unevenness. Thus, the objective is to propose a programming format that optimizes the use of resources and results in greater balance in the production of a company in the metallurgical sector, producer of road implements and located in the southern region of Brazil. Through a case study, the way of working and the situation of the company's programming were identified. From this, a model of a new production format was created, aimed at minimizing volume variations and basically based on the use of the concepts of takt time and line balancing. It is concluded that the proposed model will allow a continued pace in production, being able to stabilize it. Furthermore, as applied to the company's lines, it will highlight the points along the flow that need improvement, identifying bottlenecks and idleness. The sum of these factors will provide the continuous improvement of the company's processes and the optimization of the resources available for production.

Keywords: Production line. Production schedule. Takt time. Line balancing. Productive capacity.

\section{INTRODUÇÃO}

Com o avanço das tecnologias, a fácil disseminação da informação, o advento da globalização e o aumento da concorrência fazem com que a busca pela competitividade aumente nas empresas. Como consequência, as organizações precisam mudar e evoluir para que possam se destacar perante o mercado e se manter competitivas (AZEVEDO; ERDMANN, 2013). Nesse cenário, não se admite mais a existência de perdas ou de mau aproveitamento dos recursos, o que implica a busca constante de aperfeiçoamentos. Ao encontro disso, Simões e Alliprandini (2006) mencionam que a manutenção dos padrões de desempenho já não é mais 
suficiente para o aumento da capacidade competitiva, sendo necessárias mudanças e melhorias contínuas.

Assim, em um cenário de competição, a utilização da capacidade produtiva é um fator importante, pois, como afirma Damasio (2015), a gestão da capacidade produtiva afeta diretamente o custo de produção de um item. Outro fator relevante é a programação de produção, que tem como finalidade o gerenciamento de todos os fluxos de materiais e a utilização dos recursos da empresa (SAMPAIO et al., 2016).

Desta forma, o objetivo deste estudo consiste em propor um formato de programação que otimize a utilização dos recursos e resulte em maior equilíbrio na produção de uma empresa do ramo metalúrgico que produz implementos rodoviários e está localizada na região Sul do Brasil. Para a proposição desse modelo, foi realizado um diagnóstico do formato de programação e dos seus impactos, observando dados referentes à capacidade de produção, à alocação de recursos por centro, aos volumes, aos tempos e aos lead times.

A fim de estruturar a apresentação do artigo, este está organizado, além desta introdução, em quatro seções. São elas: referencial teórico, método de pesquisa, resultados encontrados e, por último, sugestões de melhorias e considerações finais.

\section{FUNDAMENTAÇÃO TEÓRICA}

\section{PROGRAMAÇÃO DA PRODUÇÃO}

A programação de produção faz parte do Planejamento e Controle de Produção (PCP). Na visão de Sampaio et al. (2016), tem como finalidade o gerenciamento de todos os fluxos de materiais com vistas à utilização dos recursos da empresa, sejam eles equipamentos ou pessoas, buscando responder às necessidades do cliente com base na capacidade produtiva da empresa. Assim, conforme Guerrini, Azzolini Junior e Belhot (2014), cabe à programação de produção estabelecer a carga de trabalho alocada aos equipamentos e à sequência da fabricação. Guerrini, Azzolini Junior e Belhot (2014) defendem, ainda, uma compatibilização do fornecimento com a demanda, mencionando que tal conciliação é dependente do volume e do tempo disponível para fabricação, fatores que, por sua vez, são balanceados por meio do carregamento, do sequenciamento e da programação.

Para Salvador, Guimarães e Severo (2014), o PCP tem como objetivo fazer com que máquinas e pessoas operem em níveis desejáveis de produtividade. Tubino (2017) e Salvador, Guimarães e Severo (2014), por sua vez, afirmam que o PCP deve realizar o plano conforme as expectativas de vendas, tendo como fator limitante a capacidade instalada. Assim, segundo Sampaio et al. (2016), o PCP constitui o elemento central da gestão de um sistema de produção. Os sistemas de produção podem ser divididos pelo grau de padronização dos produtos 
(produtos padronizados e sob medida) e pelo tipo de operação (processos contínuos e discretos - os processos discretos podem ser subdivididos em repetitivo em massa, repetitivo em lotes e por projeto) (TUBINO, 2017).

Cabe ressaltar, ainda, de acordo com Damasio (2015), que a capacidade da fábrica indica a disponibilidade de recursos produtivos e que a gestão dessa capacidade afeta diretamente o custo unitário de produção de um item. De acordo com o autor, a capacidade produtiva demonstra a relação entre o tempo necessário para a realização das tarefas e o tempo total disponível para a realização de uma atividade.

Ao encontro disso, Corrêa e Corrêa (2012) discorrem sobre diferentes análises de capacidade, que podem ser de longo, de médio e de curto prazo. Segundo eles, a capacidade de curto prazo - que se relaciona de forma mais direta com este estudo - pode ser de horas a dias e pode ser ajustada no nível operacional, trabalhando com a alocação de pessoas entre setores e com horas extras.

Dentro das empresas, existem formas para organizar essa distribuição e análise de capacidade. São locais chamados de centros de trabalho, que, nas palavras de Chase, Jacobs e Aquilano (2006), configuram áreas em uma empresa onde os recursos produtivos podem ser organizados e o trabalho é realizado. Podem ser uma única máquina, um grupo de máquinas ou uma área onde se realiza um tipo específico de trabalho.

A programação de centros de trabalho possui alguns objetivos, tais como cumprimento das datas de entrega, redução de lead times e diminuição de custos e de estoque em processo. A maximização do uso das máquinas e da mão de obra também é um dos objetivos; no entanto, é um objetivo polêmico, pois manter todas as máquinas e pessoas com o máximo de ocupação possível não configura o meio mais eficaz de administrar os fluxos no processo (CHASE; JACOBS; AQUILANO, 2006).

Corroborando tal perspectiva, surge uma das filosofias mais modernas de produção: o Just in Time (JIT), que, a partir de um conjunto de técnicas e de um método de planejamento e controle, visa principalmente à eliminação de desperdícios, à produção enxuta, a fluxos contínuos, à redução de estoque e à velocidade. Trata-se de um modelo surgido no Japão, na Toyota Motor Company, que diversas empresas tentam implantar devido aos benefícios existentes (SLACK; CHAMBERS; JOHNSTON, 2009).

Apesar do atingimento de altos padrões de desempenho da manufatura que é propiciado pelo JIT, alguns sacrifícios são requeridos, a exemplo da utilização da capacidade. Enquanto nos sistemas tradicionais o alto volume de estoques permite que os diversos estágios continuem produzindo, aproveitando ao máximo essa capacidade, no modelo JIT não existe ganho ou vantagem em produzir algo para deixar em estoque; somente existe vantagem em produzir alguma coisa se for para ser vendida. Outro ponto importante é que, nesse modelo, a produção extra apenas para utilização de capacidade contraria a produtividade, pois os 
estoques acabam ocultando os problemas e, assim, dificultando as melhorias no processo produtivo (SLACK; CHAMBERS; JOHNSTON, 2009).

\section{TAKT TIME}

A palavra alemã "takt", que significa "ritmo" ou "cadência", refere-se à regularidade com que algo é feito, constituindo um parâmetro de projeto amplamente usado no Sistema Toyota de Produção (FRANDSON; BERGHEDE; TOMMELEIN, 2013). O takt time é aplicado em sistemas de produção com estruturas caracterizadas pelo fluxo unitário de peças, como é o caso das linhas de montagem e das células de fabricação (ALVAREZ; ANTUNES JUNIOR, 2001), sendo responsável pelo encadeamento global do fluxo na fábrica. Trata-se, portanto, de um parâmetro que algumas empresas, especialmente as de alto desempenho, utilizam como um dos pilares fundamentais de seu sistema de produção (KAMADA, 2007) no que concerne à definição do planejamento e das estratégias empresariais, com destaque aos recursos de mão de obra, método, material e máquina (os 4 M's).

Sabe-se, ainda, que a relação entre a demanda dos clientes e a produção deve estar interligada e que o fator-chave dessa ligação é o takt time, que, conforme Almeida (2015), traduz o tempo de produção disponível pelo número de pedidos de clientes, possibilitando saber se os pedidos serão cumpridos: se o tempo de ciclo, que, segundo Simão et al. (2016), é o tempo passado entre a saída de uma peça e a saída da próxima, for maior que o takt time, haverá falta de produção (ALMEIDA, 2015). Além disso, Almeida (2015) afirma que a determinação da quantidade de postos de trabalho também faz uso do takt time, já que, quando a soma de todos os tempos das tarefas individuais é dividida pelo takt time, tem-se o número de postos de trabalho necessário para cumprir a demanda de mercado.

Ademais, para conhecer o takt time de uma empresa, basta dividir o tempo diário de produção disponível pelo número de produtos a serem produzidos por dia. Assim, toda a empresa deve adaptar seus recursos e processos para que as operações ocorram dentro do takt time e a demanda do cliente possa ser atendida. Para conseguir esse equilíbrio entre o que o cliente demandou e o que a fábrica consegue produzir, deve-se fazer o balanceamento das linhas de produção (PRADO, 2016).

Becker e Scholl (2006) consideram que, quando se configura ou reconfigura uma linha de montagem, o balanceamento de linhas deve ser aplicado, a fim de distribuir a carga total de trabalho para a fabricação de qualquer unidade de um produto a ser montado entre as estações de trabalho ao longo da linha de produção. Para Almeida (2015), em uma linha de produção, existem questões importantes que devem ser tratadas, tais como definição de tempos de ciclo, delimitação do número de postos de trabalho e balanceamento da linha de produção.

Segundo Leite et al. (2017), o balanceamento de linha permite aumentar a eficiência de um processo produtivo, existindo, conforme Oliveira e Borges (2016), algumas etapas 
básicas recomendadas: determinar as tarefas a serem executadas para fabricar uma unidade do produto; definir a sequência em que devem ser executadas, e, se houver uma relação de precedência, essa deve ser identificada; estimar a duração de cada tarefa e o tempo de ciclo; calcular os postos de trabalho necessários; e atribuir as tarefas nas estações de trabalho (BATTAÏA; DOLGUI, 2013).

Após a realização do balanceamento de linha, é importante saber o quanto da capacidade está sendo utilizada e o quanto eficaz foi a distribuição das tarefas. Para isso, existem dois indicadores: a eficiência da linha e a eficiência do balanceamento. O primeiro, que mostra a utilização da linha em termos percentuais, é obtido dividindo-se a soma dos tempos de todas as tarefas pela multiplicação do número de postos de trabalho pelo takt time - quanto mais próximo de 100\%, maior o aproveitamento. O segundo, que demonstra a eficácia da distribuição das tarefas nos postos de trabalho, é dado dividindo-se a soma dos desvios de tempo de cada posto de trabalho em relação à média de tempo de todos os postos pela multiplicação do número de postos de trabalho pelas médias de tempo de todos os postos de trabalho (ALMEIDA, 2015).

Um ponto importante a ser destacado é que, no caso do modelo de produção da empresa em estudo, os produtos não possuem tempos iguais. Conforme Diniz e Calife (2015), em casos como esse, o tempo a ser utilizado para os cálculos supracitados é o tempo ponderado. Para obtê-lo, é preciso multiplicar o tempo de operação para cada produto pelo seu volume de produção e, depois, somar todos esses tempos e dividi-los pela soma do volume total a ser produzido.

\section{MÉTODO DA PESQUISA}

Esta pesquisa possui abordagem qualitativa, pois foca o contato direto e intensivo do pesquisador com a situação que está sendo investigada. Além disso, apresenta o objetivo exploratório, pois possibilita o aprimoramento de ideias e possui um planejamento flexível, o que propicia considerações sobre os aspectos relativos ao fato estudado (COOPER; SCHINDLER, 2016).

Como estratégia de pesquisa, adotou-se o estudo de caso. Segundo Yin (2015), o foco desses estudos consiste em fenômenos contemporâneos inseridos em algum contexto da vida real, com vistas a compreender fenômenos sociais complexos. O estudo de caso permite uma investigação que preserva as características holísticas e significativas dos eventos da vida real.

Ressalta-se, contudo, que, a coleta de dados em estudos de caso é a mais complexa que nos demais tipos de estudo - enquanto estes possuem técnicas específicas, aqueles podem utilizar mais de uma técnica, sendo imprescindível a busca de várias fontes para garantir a validade da investigação (YIN, 2015). Para este estudo, foi realizada a coleta de dados nos 
registros do Sistema de Gestão Empresarial (ERP) da empresa, buscando informações de capacidade e de demanda de trabalho alocado nos centros de trabalho e informações de volumes programados para identificar os desnivelamentos. Além disso, empregou-se a observação participante (ANGROSINO, 2009) do processo inicial para identificar a interação existente entre os centros, bem como o fluxo do produto.

Portanto, para esta investigação, foi efetuada a triangulação dos dados (registros da empresa, observação participante e literatura), conforme sugerem Denzin e Lincoln (2011). O período de análise considerou o intervalo de janeiro a junho de 2017.

\section{UNIDADE DE ANÁLISE}

O ambiente deste estudo é a maior fabricante de reboques e semirreboques da América Latina, com matriz em Caxias do Sul, cidade situada na região Sul do Brasil. A empresa produz implementos rodoviários de diferentes tipos (graneleiro, carga seca, tanque, basculante, silo, frigorífico, canavieiro, florestal, furgão e outros). Suas linhas de montagem são divididas em quatro grandes grupos: montagem de bases, montagem de caixas, pintura e montagem final. Dentro de uma linha de montagem, podem existir um ou mais centros de trabalho, e cada linha pode produzir um modelo específico de produto ou vários modelos. Nessa empresa, existem também outros centros de trabalho que produzem componentes para as linhas já citadas, mas que não integram o escopo deste estudo.

O tempo de mão de obra direta disponível para produzir esses produtos, no momento da coleta de dados, era de aproximadamente 11.200 horas por dia, sem descontar nenhum tipo de ineficiência. O setor de PCP da empresa distribui as ordens de fabricação com base no plano de produção, que é oriundo do processo de Planejamento Tático de Vendas e Operação (PTVO). Nesse plano, consta o volume diário de cada modelo de produto a ser produzido, e, conforme são colocadas as ordens de produtos para clientes ou para estoque, os centros de trabalho vão sendo preenchidos com cargas de trabalho.

\section{RESULTADOS E DISCUSSÃO}

\section{FORMATO INICIAL DE PROGRAMAÇÃO}

Ao observar o formato inicial de programação da empresa investigada, notou-se que o setor de programação recebe mensalmente um plano de demanda, em que constam um volume de produção e um plano de mão de obra. O volume corresponde à quantidade de cada um dos produtos que deve ser fabricado diariamente, e essa informação é dada por um modelo genérico de produto. Para a família graneleira, por exemplo, há um volume para semirreboques, bitrens e rodotrens, e o plano de mão de obra mostra a quantidade de pessoas 
planejadas para cada centro de trabalho para executar o plano. O plano de demanda é disponibilizado para um período de três meses, além do mês corrente.

Além disso, existe um período no qual, obrigatoriamente, faz-se a colocação de pedidos para preencher o volume do plano de demanda, trabalho esse chamado de fechamento do período firme. Esses pedidos são produtos para clientes; no entanto, os pedidos que chegam para a programação nem sempre condizem com o plano acordado, e, muitas vezes, são programados produtos para estoque. O que ocorre nesse momento é que, conforme são programadas as ordens de produção, os centros de trabalho são preenchidos com cargas de horas de trabalho. Como os produtos não são iguais dentro de sua família e dentro de seu modelo genérico, eles possuem variações de características, como, por exemplo, comprimento, tipo de suspensão, aplicação e tipo de assoalho. Assim, a alteração dessas características afeta diretamente a complexidade da sua fabricação e a quantidade de horas produtivas que cada um possui em determinado centro de trabalho.

Um dos problemas encontrados diz respeito à necessidade de completar toda a carga do centro de trabalho, pois um dos indicadores mais importantes da empresa é a ociosidade. Entretanto, ao mesmo tempo, é necessário cumprir o plano de demanda para atender as metas comerciais e financeiras, de modo que alcançar os dois objetivos nem sempre é possível. Em meio a esse processo, ocorre um evento denominado validação, em que o programa que está para ser fechado é apresentado ao setor de produção, setor esse que emite seu parecer informando se poderá ou não executar o plano.

Observou-se, ainda, que a maioria dos centros de trabalho dessa empresa é constituída de linhas de produção que possuem boxes de trabalho, mas a informação disponível para as áreas trabalharem é um montante de horas disponíveis versus um volume a ser produzido. Ao final, o resultado consiste em um plano exequível que não atenderá à expectativa ou ao indicador de alguma área da empresa, explicitando que o formato inicial não é adequado para a empresa, conforme Figura 1.

Figura 1 - Esquema do modelo de programação da empresa

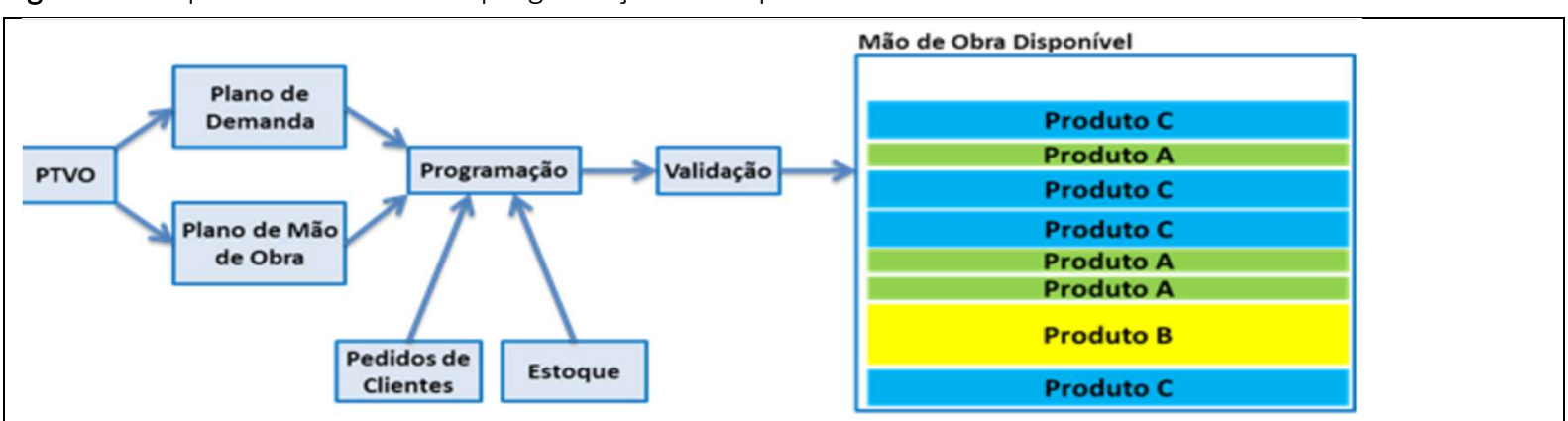

Fonte: Elaborada pelos autores (2021).

A empresa em estudo possui cerca de 30 centros de trabalho que fazem os processos de solda, pintura e montagem dos produtos - existem outros centros que fazem componentes para os produtos, mas que não estão no escopo deste estudo. Esses centros são divididos em 
grandes grupos, chamados de minifábricas. Cada centro possui interação com outro centro ou com uma minifábrica, de modo que o produto passa de centro em centro até chegar à montagem final e ficar disponível para venda. Vale destacar que um centro de trabalho recebe produtos de diversos outros centros de trabalho.

Ademais, cada produto, em cada centro, possui um lead time cadastrado na sua ordem de produção. Esse tempo é definido conforme a expectativa de duração do atravessamento do produto no centro de trabalho, e, no mesmo centro de trabalho, existem produtos com tempos de duração diferentes cadastrados. O fato de que o mesmo centro possui tempos de lead times diferentes, somado ao fato de que existe variação no volume devido ao formato inicial de programação, causa um desnivelamento no volume diário de produtos nos centros subsequentes. Como consequência, há oscilação na demanda, pois, em um dia, existe excesso e, no outro, escassez de demanda. Essa oscilação aumenta conforme o fluxo de produção e, nos centros finais, onde ocorre a última etapa da produção, torna-se um fator crítico para o cumprimento da programação validada. A Figura 2, exposta a seguir, exemplifica como estão distribuídos os centros de trabalho e como ocorrem a interação e o fluxo de produção da empresa.

Figura 2 - Centros de trabalho e fluxo de produção da empresa

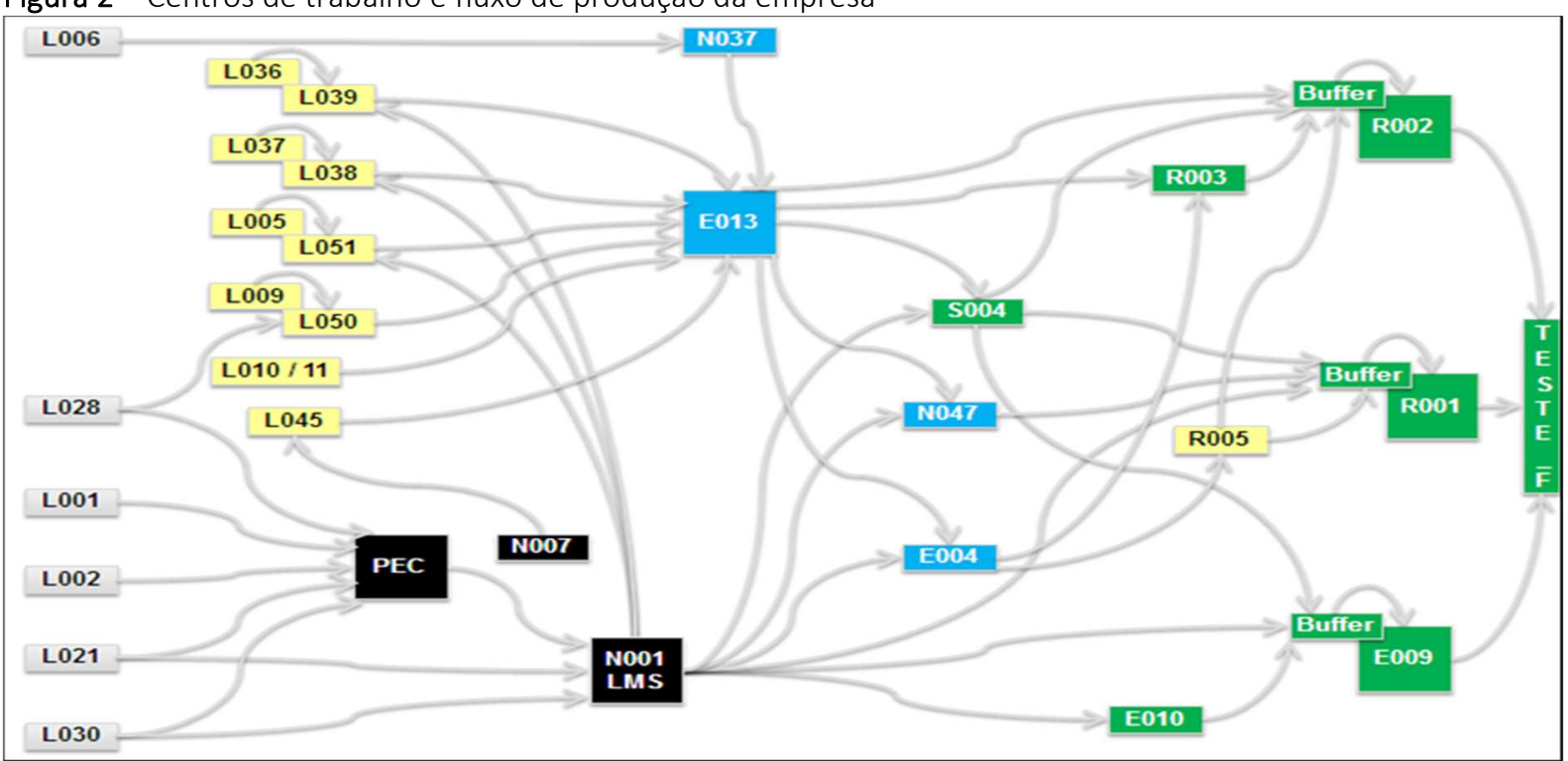

Fonte: Elaborada pelos autores (2021).

Como a indústria investigada possui uma quantidade considerável de centros de trabalho, para o modelo proposto, optou-se por um centro de trabalho localizado no início do fluxo, pois ele sofre menos oscilação em função de outros centros e o seu layout físico da linha já apresenta uma divisão por box. O centro escolhido foi o L002, que faz parte da minifábrica de bases. Nessa linha, são feitas operações de montagem e solda nas bases para produtos da família graneleira, carga geral e frigorífica.

A partir disso, foram selecionadas todas as ordens programadas no período de análise, 
verificando-se o quanto o volume de produção e as cargas de trabalho oscilaram. Nas linhas de base, $50 \%$ do volume oscilou entre 47 e 66 produtos por dia. Entretanto, houve um dia em que 20 produtos tinham sido programados e outro em que 75 produtos foram programados. Nas linhas de montagem final, esse número variou entre 42 e 62, com mínimo de 20 e máximo de 80 produtos. Já nas linhas de caixa e pintura, 50\% do volume oscilou entre 13 e 18, com mínimo de 5 e máximo de 25 produtos por dia.

Em relação ao lead time, percebeu-se que todas as linhas de produção possuem produtos com tempos de atravessamento diferentes dentro da mesma linha - algumas com variação de um dia apenas, outras com variação de até quatro dias entre produtos na mesma linha. Notou-se, também, que essa variação pode ocorrer dentro do mesmo dia ou da mesma semana.

Em relação às horas para a análise do todo, foi verificada a soma total da carga de trabalho (semana a semana) dos centros em análise, o que permitiu identificar que não existe uma constância de volume de carga programada. A variação percebida na maioria das semanas foi de até 400 horas, mas houve um período entre as semanas 41 e 44 em que a diferença chegou a ser de 1.200 horas.

Com esses dados, já é possível verificar os distúrbios causados pela forma de programação inicial e pelo uso da capacidade, mas, para uma análise mais aprofundada, detalhou-se o que ocorre no centro escolhido como piloto. A Figura 3 apresenta a situação conforme o modelo da empresa, representada em cargas de trabalho por box ao longo do tempo.

Figura 3 - Distribuição de volumes e horas do centro-piloto da empresa ao longo do tempo

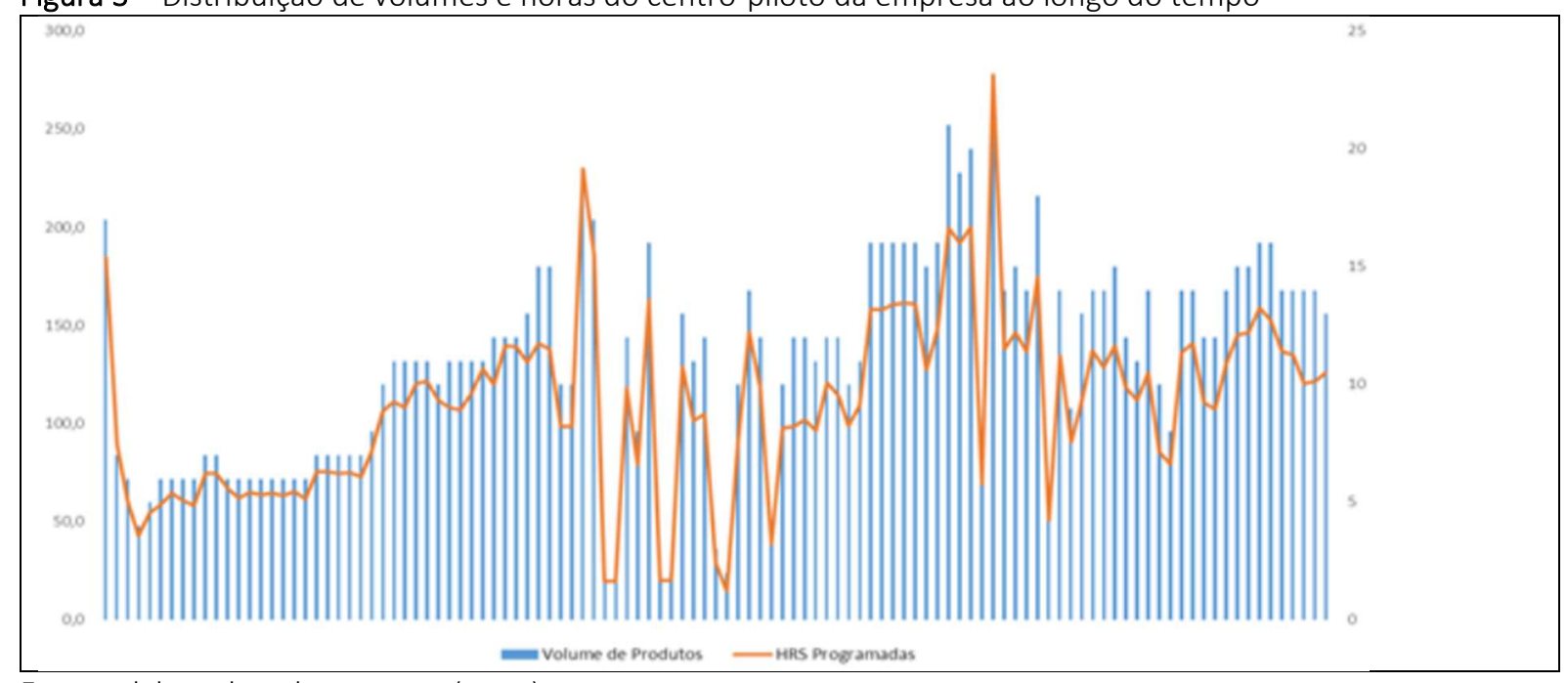

Fonte: Elaborada pelos autores (2021).

No centro-piloto, foram programados 1.224 produtos no período em análise, uma carga total de 12.211 horas de produção e 32 modelos diferentes separados em três famílias de produtos. O Gráfico 1, a seguir, mostra a distribuição ao longo do tempo dos volumes de 
produtos programados e a carga de horas programadas diariamente. As barras representam o volume de produtos em uma escala de 0 a 25, e a linha representa a quantidade de horas em uma escala de 0 a 300.

A falta de definição de um takt time e de uma análise de balanceamento deixa claro que, em alguns momentos, existe ociosidade e, em outros, não é possível cumprir o programa. Além disso, o fato de o modelo inicial considerar a linha como um todo, sem o balanceamento, também poderia ocultar algum box gargalo. A Figura 4 apresenta a variação que existe entre o que foi programado e o que foi realizado, mostrando que não há congruência entre os dois fatores.

Figura 4 - Variação entre horas programadas e realizadas ao longo do tempo no centro-piloto da empresa

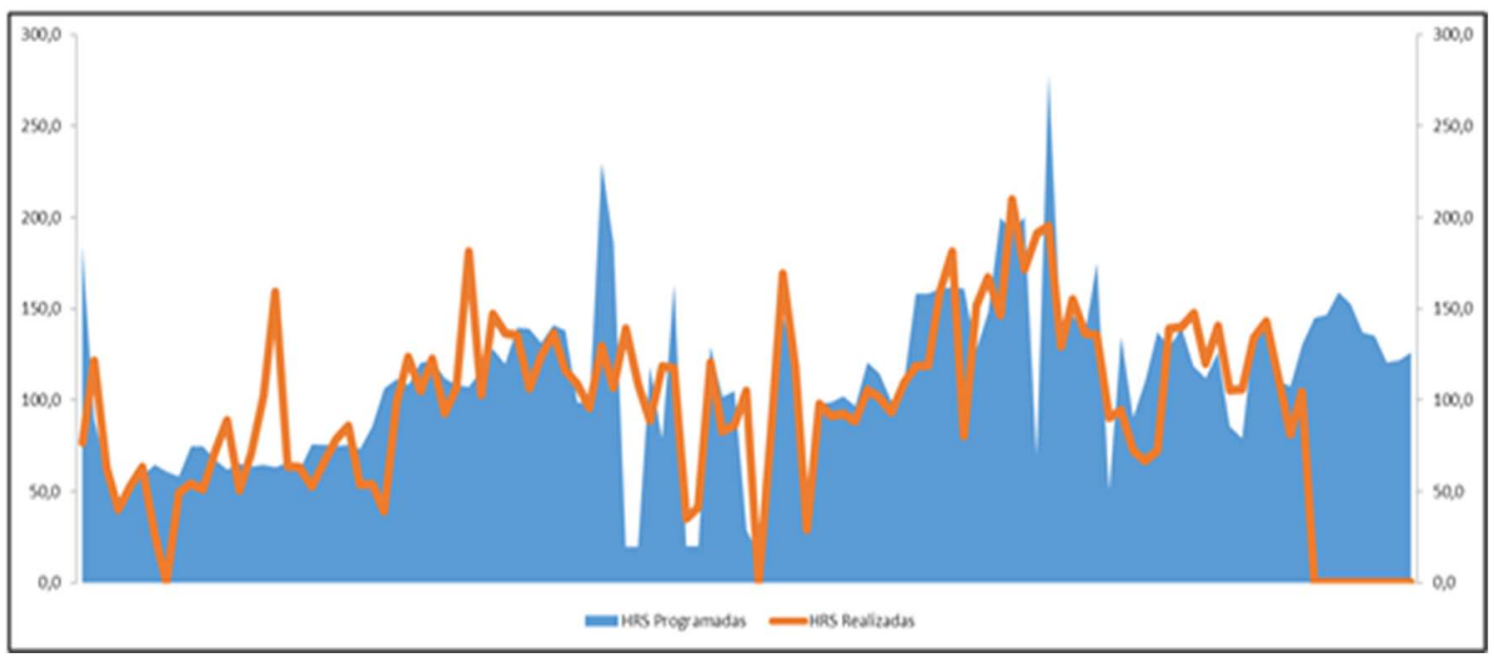

Fonte: Elaborada pelos autores (2021).

É sabido, ainda, que existem outras perdas no processo que podem alterar o volume realizado. Todavia, como o balanceamento não é feito e os limites e os gargalos ao longo da linha são desconhecidos, isso também pode ser elencado como fator de distúrbio.

\section{PROPOSTA DE MELHORIA}

A proposta de melhoria deste estudo consiste em implementar o conceito de takt time e de balanceamento de linha, pois, como mencionado, é o formato ideal para organizações com o modelo de produção da empresa em estudo. Com o balanceamento, será possível organizar e conferir um ritmo ao fluxo de produção, permitindo a identificação de operações gargalos e a otimização do processo.

A empresa não possui, em seus roteiros de produção, o detalhamento das operações dentro dos boxes de trabalho, apenas o tempo total de carga de trabalho em cada box. Portanto, foi possível simular somente o takt time e o tempo de ciclo e o número de postos de trabalho, sem o balanceamento. Para isso, depois de medir o volume por dia de produção do mês de junho de 2017, foram previstos o plano de demanda para os produtos que passam 
nessa linha e os roteiros de produção padrão para todos os modelos desses produtos.

Nesse cálculo, o takt time é de 41,5 minutos por produto, já que há 498 minutos disponíveis por dia para um volume de 12 produtos. O tempo de ciclo e o número mínimo teórico de postos de trabalho podem ser vistos na Tabela 1.

Tabela 1 - Tempos de ciclo por modelo e por box com cálculo do número de postos de trabalho da empresa

\begin{tabular}{c|c|c|c|c|c|c|c|c|c|c|c|c}
\hline Modelo & Box 01 & Box 02 & Box 03 & Box 04 & Box 05 & Box 06 & Box 07 & Box 08 & Box 09 & $\begin{array}{c}\text { Tempo de } \\
\text { Ciclo (Mi N) }\end{array}$ & Cálculo & $\begin{array}{c}\text { N॰ Postos de } \\
\text { Traba Iho }\end{array}$ \\
\hline A & 83,7 & 27,0 & 84,0 & 29,1 & 165,7 & 17,5 & 72,0 & 105,3 & 7,8 & 592,0 & 14,3 & 15 \\
\hline B & 90,7 & 27,0 & 92,2 & 29,1 & 176,7 & 17,5 & 79,1 & 116,6 & 7,8 & 636,8 & 15,3 & 16 \\
\hline C & 108,5 & 21,1 & 75,5 & 20,2 & 127,2 & 13,8 & 55,8 & 86,7 & 7,8 & 516,6 & 12,4 & 13 \\
\hline D & 86,1 & 21,1 & 62,2 & 20,5 & 198,4 & 14,4 & 31,9 & 61,6 & 7,8 & 504,0 & 12,1 & 13 \\
\hline E & 95,1 & 27,0 & 97,4 & 29,1 & 183,5 & 17,5 & 83,6 & 123,7 & 7,8 & 664,8 & 16,0 & 17 \\
\hline F & 83,7 & 27,0 & 84,0 & 29,1 & 165,7 & 17,5 & 72,0 & 105,3 & 7,8 & 592,0 & 14,3 & 15 \\
\hline G & 121,2 & 21,1 & 84,9 & 20,2 & 139,6 & 13,8 & 63,4 & 98,0 & 7,8 & 570,0 & 13,7 & 14 \\
\hline H & 83,7 & 27,0 & 84,0 & 20,5 & 165,7 & 14,4 & 72,0 & 105,3 & 7,8 & 580,3 & 14,0 & 14 \\
\hline I & 88,5 & 27,0 & 89,7 & 29,1 & 173,2 & 17,5 & 76,9 & 113,1 & 7,8 & 622,8 & 15,0 & 16 \\
\hline J & 133,3 & 21,1 & 93,7 & 20,2 & 151,3 & 13,8 & 70,6 & 108,7 & 7,8 & 620,6 & 15,0 & 15 \\
\hline K & 78,9 & 27,0 & 78,3 & 20,5 & 158,2 & 14,4 & 67,1 & 97,6 & 7,8 & 549,8 & 13,2 & 14 \\
\hline L & 135,0 & 21,1 & 95,0 & 20,2 & 153,0 & 13,8 & 71,6 & 110,2 & 7,8 & 627,6 & 15,1 & 16 \\
\hline IA & 83,7 & 27,0 & 84,0 & 29,1 & 165,7 & 17,5 & 72,0 & 105,3 & 7,8 & 592,0 & 14,3 & 15 \\
\hline N & 88,5 & 27,0 & 89,7 & 29,1 & 173,2 & 17,5 & 76,9 & 113,1 & 7,8 & 622,8 & 15,0 & 16 \\
\hline D & 113,0 & 21,1 & 78,8 & 20,2 & 131,5 & 13,8 & 58,5 & 90,7 & 7,8 & 535,4 & 12,9 & 13 \\
\hline P & 89,3 & 21,1 & 64,8 & 20,5 & 201,4 & 14,4 & 33,3 & 64,2 & 7,8 & 516,7 & 12,5 & 13 \\
\hline Q & 87,7 & 27,0 & 88,7 & 29,1 & 171,9 & 17,5 & 76,0 & 111,7 & 7,8 & 617,5 & 14,9 & 15 \\
\hline
\end{tabular}

Fonte: Elaborada pelos autores (2021).

Diante disso, a orientação para a empresa é de que, inicialmente, faça o detalhamento das operações dentro do seu roteiro e, após, realize um diagrama de precedência entre as operações e aloque as operações nos postos de trabalho, respeitando o takt time. Com isso, poderão ser observadas oportunidades de melhorias, em relação às quais a área de engenharia de processo poderá atuar. A Figura 5 apresenta o modelo proposto de linha de programação.

Figura 5 - Modelo proposto de programação da empresa

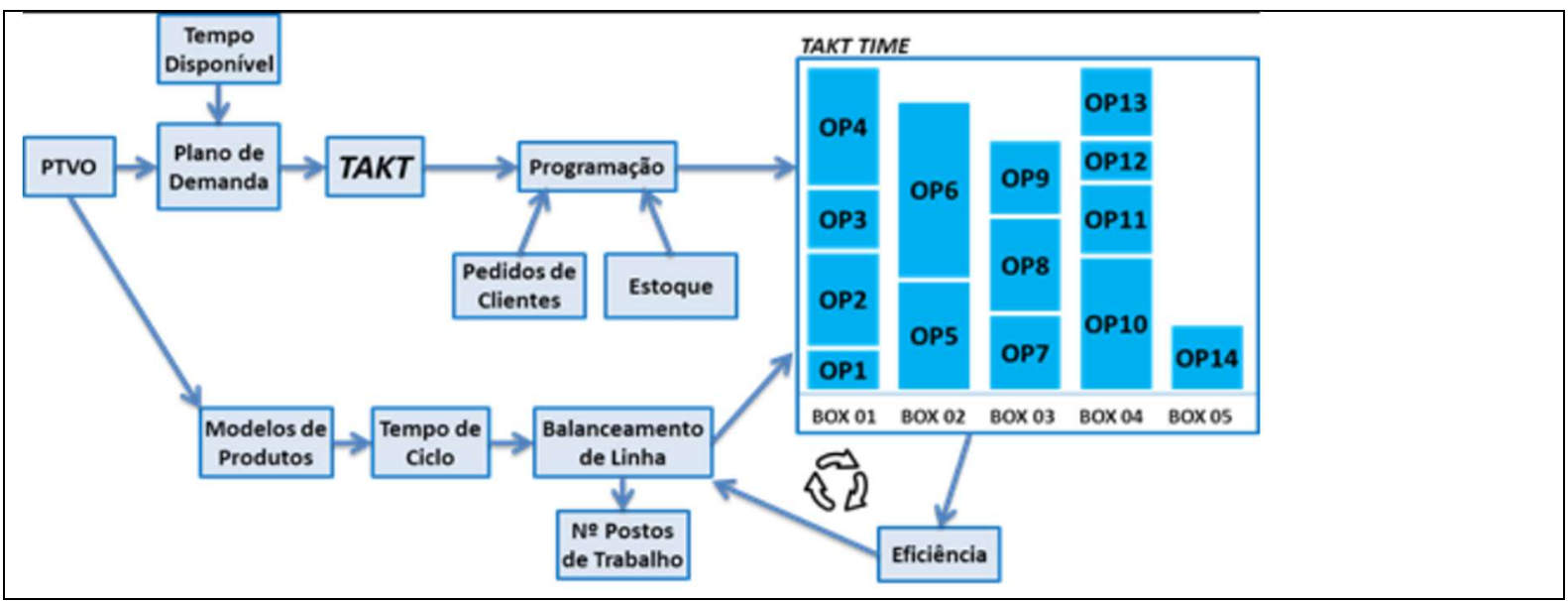

Fonte: Elaborada pelos autores (2021).

Aconselha-se, também, que a empresa calcule a eficiência da linha e do balanceamento na primeira vez, para que, depois de implementadas as melhorias, seja possível comparar e comprovar a evolução desse indicador. Quanto ao problema do nivelamento, como 
o modelo inicial de programação é o principal ofensor, ao implementar o conceito de takt time, as oscilações de volume diminuirão, pois haverá um ritmo padrão nas linhas. Assim que forem conhecidas as operações de cada linha e realizado o balanceamento, não poderá mais haver dúvida entre privilegiar horas ou volume, pois a regra deverá ser o takt time e a área de programação deverá carregar os centros de trabalho conforme o volume definido.

É sabido que, mesmo com tais medidas, ainda haverá ociosidade. No entanto, por intermédio do balanceamento, será possível identificar os postos de trabalho ociosos e alocar mais tarefas a eles ou transferir a operação para outro posto, eliminando-os. O mesmo acontecerá nos postos em que o tempo de ciclo for maior que o takt time, devendo ser retiradas operações do posto ou feitas melhorias de processo, a fim de diminuir esse tempo.

A proposta consiste, portanto, em a empresa adotar a regra do takt time como forma de programação e trabalhar com o balanceamento. Além disso, outro ponto que deverá ser ajustado é o cadastro de lead time no roteiro dos produtos, já que, em uma linha de produção com um ritmo estabelecido, não pode haver produtos com diferentes lead times. Assim, após a identificação do lead time de cada linha, este deve ser cadastrado para todos os produtos que passam pela linha.

\section{ANÁLISE E INTERPRETAÇÃO DOS RESULTADOS}

Ao verificar a situação inicial da linha de produção da empresa pesquisada, percebeuse que existia uma divergência de expectativa, bem como um conflito de interesses, entre áreas da empresa: de um lado, objetivava-se seguir um plano com um número definido e, de outro, consideravam-se horas de produção como um todo, em linhas de produção que contavam com diversas operações ao longo de seu fluxo. Notou-se, também, falta de padronização em relação ao cadastro dos lead times no sistema, de modo que, na mesma linha com fluxo único, existiam diferenças de dias entre os produtos.

O setor de programação, por sua vez, tentava equilibrar esses fatores e atender às expectativas, montando um programa validado como exequível. No entanto, os resultados apresentados evidenciaram que a falta de uma regra e de um formato claro e definido de como a empresa deveria trabalhar estava ocasionando problemas. As principais complicações identificadas - e expostas neste estudo - foram o desnivelamento entre os centros de trabalho ao longo do fluxo produtivo e a forma como, individualmente, estavam carregados com horas. Consequentemente, existiam períodos com ociosidade e outros com sobrecarga.

Assim, com base na identificação do modo de funcionamento da empresa e de seu sistema de produção e no referencial teórico utilizado para embasar este estudo, sugeriu-se a maneira como a empresa deve trabalhar. O formato proposto é fundamentado no uso do conceito de takt time, que define um ritmo padrão para a linha de produção conforme o volume de produtos. No entanto, esse conceito traz consigo outros fatores, como a organização e o 
mapeamento das operações ao longo da linha, o que, por sua vez, permitirá que a empresa conheça o seu tempo de ciclo, podendo definir se atenderá ou não ao volume solicitado pelo cliente. Essa regra contempla, também, a possibilidade de realização do balanceamento da linha de produção, identificando gargalos e oportunidades de melhorias, bem como a definição do número de postos de trabalho necessários e o melhor aproveitamento da capacidade produtiva.

Em relação ao desnivelamento, a proposta de mudança é mais simples de ser executada: basta verificar o tempo de atravessamento do produto na linha e cadastrar esse mesmo tempo, que é o lead time, para todos os produtos que passam na linha, mantendo, consequentemente, um padrão e equilibrando os volumes de produção ao longo do fluxo produtivo. Desse modo, seguindo o que foi proposto como melhoria, os resultados esperados para a empresa consistem em um equilíbrio entre o plano de demanda e a produção realizada; uma fábrica e linhas de produção mais estáveis, com um ritmo constante; e um fluxo de produção entre centros mais constante e nivelado, com menos perdas.

O que se espera, portanto, é o melhor aproveitamento da capacidade produtiva e a melhoria contínua dos processos, pois, ao realizar os mapeamentos das linhas e o balanceamento, ficaram evidentes os locais que requerem melhorias de processo, melhorias essas que, depois de implementadas, passarão por um novo balanceamento, que evidenciará outras oportunidades, de forma contínua. Sequencialmente, aparecerão produtos que a linha terá maior dificuldade de produzir ou não conseguirá produzir dentro do mesmo takt time que os demais - esses produtos deverão ter seus processos e projetos revisados, assim como seu ganho real e sua viabilidade de comercialização discutidos.

\section{CONSIDERAÇÕES FINAIS}

Os problemas encontrados na empresa em estudo foram, principalmente, a falta de uma regra clara para programação e preenchimento da carga de trabalho nas linhas de produção, o que, por consequência, causava oscilação de volume de produção e de horas, além do desnivelamento de produção entre centros. Pode-se afirmar que o formato inicial ocultava ineficiências da linha e a viabilidade de alguns modelos de produtos.

A partir da pesquisa realizada, foi proposto um modelo a ser seguido pela empresa. Esse modelo permitirá conferir ritmo e estabilidade à produção e, conforme for aplicado nas linhas da empresa, evidenciará os pontos ao longo do fluxo que precisam de melhoria, identificando gargalos e ociosidades. O resultado proporcionará a melhoria contínua dos processos empresariais.

O modelo proposto foi avaliado pela empresa como um primeiro passo para a busca do equilíbrio e da otimização de seu processo produtivo. Assim, após a definição de um modelo 
que é o ideal para o seu sistema de produção, esse modelo deverá ser visto como uma regra de negócio da empresa, norteando os próximos passos. Ademais, a empresa deverá conciliar a demanda da área comercial com a linha de produção, para que a preferência por determinados clientes ou entregas não interfira no andamento da linha de produção.

Com isso, para investigações futuras, sugere-se realizar o mapeamento e o balanceamento de uma linha de produção por meio de uma pesquisa-ação, a fim de mensurar os dois estágios e propiciar, assim, que a empresa veja os resultados anteriores e posteriores à alteração na linha de produção. Ainda, sugerem-se estudos de simulação e sequenciamento de montagens de mix para otimização e de implementação de softwares com essas finalidades. Essas são algumas sugestões para estudos que somente podem ser pensados a partir do uso do takt time proposto neste artigo.

\section{REFERÊNCIAS}

ALMEIDA, R. E. H. de. Balanceamento de Linhas de Produção, 2015. Dissertação (Mestrado) Universidade de Aveiro, Departamento de Economia, Gestão e Engenharia Industrial, 2015. Disponível em: <http://docplayer.com.br/20957227-Balanceamento-de-linhas-deproducao.html>. Acesso em 13 de jun. 2017.

ALVAREZ, R. R.; ANTUNES JUNIOR, J. A. V. Takt-time: conceitos e contextualização dentro do Sistema Toyota de Produção. Gestão \& Produção, São Carlos, v. 8, n. 1, p.1-18, 2001.

ANGROSINO, M. Etnografia e observação participante. Porto Alegre: Artmed, 2009.

AZEVEDO, B. M. de; ERDMANN, R. H. A Busca da Competitividade Organizacional a Partir da Adoção de Melhores Práticas de Gestão do Sistema de Produção. In: ENCONTRO NACIONAL DE ENGENHARIA DE PRODUÇÃO - ENEGEP, 2013, Salvador. Anais... Salvador: Enegep, p. 1-12, 2013.

BATTAÏA, O.; DOLGUI, A. A taxonomy of line balancing problems and their solutionapproaches. International Journal Of Production Economics, Saint-etienne, v. 142, n. 2, p. 259-277, 2013.

BECKER, C.; SCHOLL, A. A survey on problems and methods in generalized assembly line balancing. European Journal Of Operational Research, Jena, v. 168, n. 3, p. 694-715, 2006.

CHASE, R. B.; JACOBS, F. R.; AQUILANO, N. J. Administração da Produção para a Vantagem Competitiva. 11. ed. São Paulo: McGraw-Hill, 2006.

COOPER, D. R.; SCHINDLER, P. S. Métodos de Pesquisa em Administração. 12. ed. Porto Alegre: Bookman, 2016.

CORRÊA, H. L.; CORRÊAA, C. A. Administração de Produção e Operações. 3. ed. São Paulo: Atlas, 2012. 
DAMASIO, J. V. P. et al. Análise de Capacidade Produtiva Utilizando Estudos de Tempos e Métodos: estudo de caso no setor de embalagens de uma empresa de fabricação de MDF. In: ENCONTRO NACIONAL DE ENGENHARIA DE PRODUÇÃO - ENEGEP, 2015, Fortaleza. Anais... Fortaleza: Enegep, 2015. p. 1-17.

DENZIN, N. K.; LINCOLN, Y. S. (ed.). The Sage handbook of qualitative research. 4. Ed. Estados Unidos: Sage, 2011.

DINIZ, N. O. S.; CALIFE, N. F. S. Cronoanálise e Balanceamento de Linha de Montagem: estudo de caso em uma montadora de veículos. In: ENCONTRO NACIONAL DE ENGENHARIA DE PRODUÇÃO - ENEGEP, 2015, Fortaleza. Anais... Fortaleza: Enegep, p. 1-18, 2015.

FRANDSON, A.; BERGHEDE, K.; TOMMELEIN, I. D. Takt Time Planning for Construction of Exterior Cladding. In: 21TH ANNUAL CONFERENCE OF THE INTERNATIONAL GROUP FOR LEAN CONSTRUCTION, 2013, Fortaleza. Proceedings... Fortaleza: IGLC, p. 527-536, 2013.

GODOY, A. S. Introdução à pesquisa qualitativa e suas possibilidades. Revista de Administração de Empresas, São Paulo, v. 35, n. 2, p. 57-63, 1995.

GUERRINI, F. M.; AZZOLINI JUNIOR, W.; BELHOT, R. V. Planejamento e Controle da Produção: projeto e operação de sistemas. Rio de Janeiro: Elsevier, 2014.

KAMADA, S. Estabilidade na Produção da Toyota do Brasil, 2007. Disponível em: <https://www.lean.org.br/artigos/86/estabilidade-na-producao-da-toyota-do-brasil.aspx/>. Acesso em: 09 de jun. 2017.

LEITE, M. S. et al. Eficácia da heurística da utilização incremental para balanceamento de linha: estudo de caso em um processo de tratamento de superfície. Revista Produção Online, Florianópolis, v. 17, n. 3, p. 781-803, 15 set. 2017.

OLIVEIRA, F. S.; BORGES, R. Proposta de Melhorias no Balanceamento de uma Linha de Montagem de Eixos em uma Montadora de Veículos Pesados. In: ENCONTRO NACIONAL DE ENGENHARIA DE PRODUÇÃO - ENEGEP, 2016, João Pessoa. Anais... João Pessoa: Enegep, p. 115, 2016.

PRADO, M. et al. Análise da Aplicação da Teoria das Restrições na Linha de Manufatura de uma Indústria de Produtos Bélicos. In: ENCONTRO NACIONAL DE ENGENHARIA DE PRODUÇÃO - ENEGEP, 2016, João Pessoa. Anais... João Pessoa: Enegep, p. 1-17, 2016.

SALVADOR, M. F.; GUIMARÃES, J. C. F.; SEVERO, E. A. Programação e Sequenciamento da Produção: o caso de uma montadora de Implementos Rodoviários. DESENVOLVE: Revista de Gestão do Unilasalle, Canoas, v. 3, n. 2, p. 111-128, set. 2014.

SAMPAIO, D. M. et.al. Aplicação do Excel Integrado ao MS-Project em uma Empresa do Ramo da Construção Civil Localizado no Município de Marabá-PA. In: ENCONTRO NACIONAL DE ENGENHARIA DE PRODUÇÃO - ENEGEP, 2016, João Pessoa. Anais... João Pessoa: Enegep, p. 114, 2016. 
SIMÃO, V. G. et.al. Aplicação da Teoria das Restrições em uma Produção Industrial Farmacêutica: Um Estudo de Caso. In: ENCONTRO NACIONAL DE ENGENHARIA DE PRODUÇÃO - ENEGEP, 2016, João Pessoa. Anais... João Pessoa: Enegep, p. 1-17, 2016.

SIMÕES, R.; ALLIPRANDINI, D. H. Gestão da Melhoria Contínua: modelo de boas práticas e aplicação em uma empresa de médio porte. In: ENCONTRO NACIONAL DE ENGENHARIA DE PRODUÇÃO - ENEGEP, 2006, Fortaleza. Anais... Fortaleza: Enegep, p. 1-9, 2006.

SLACK, N.; CHAMBERS, S.; JOHNSTON, R. Administração da Produção. 3. ed. São Paulo: Atlas, 2009.

TUBINO, D. F. Planejamento e Controle da Produção: teoria e prática. 3. ed. São Paulo: Atlas, 2017.

YIN, R. K. Estudo de caso: Planejamento e Métodos. 5. ed. São Paulo: Bookman, 2015. 